\title{
Vínculo e Aliança Inconsciente: reflexões a partir de entrevista com criança com sequela oncológica
}

\author{
Milena Dórea de Almeida* \\ Ana Paula Alves Lima Santos**
}

\begin{abstract}
Resumo
Este trabalho trata da noção de vínculo e de aliança inconsciente à luz da Psicanálise das Configurações Vinculares, que tem como base a Psicanálise Freudiana, porém estende seu campo de abordagem para o grupo. O vínculo é o principal conceito que singulariza esta teoria, pois aponta para a existência de um aparelho psíquico grupal e exige a triangulação eu - outro(s) - conector, em que o conector é o que existe de comum e sustenta o vínculo. A discussão será ilustrada com trechos de uma entrevista realizada com Tiago, uma criança que teve tumor de sistema nervoso central (SNC), estava fora de tratamento oncológico e apresentava rebaixamento da visão decorrente da doença e da terapia oncológica. Discute-se a posição dele no grupo familiar como "porta-sintoma” de uma situação angustiante. Há uma aliança de mal entendido em torno da sequela permanente e ele adota uma posição passiva para proteger os pais da angústia. A inserção do psicanalista nos centros especializados de tratamento do câncer infantil abre a possibilidade de intervenções em situações em que os pais negam as angústias e as dificuldades. Há a aposta que, proporcionando um espaço para serem escutadas e observadas questões referentes à dinâmica familiar, podem-se esclarecer os lugares de cada membro e trabalhar no sentido de favorecer a elaboração do que está sendo vivido, contribuindo para a formação de vínculos menos alienantes.

Palavras Chaves: Psicanálise das Configurações Vinculares, Aliança Inconsciente, Tumor de sistema nervoso central.
\end{abstract}

\section{Bond and Unconscious Alliance: reflections from interview with child with oncologic sequela}

\begin{abstract}
This paper deals with the notion of unconscious alliance in the light of the Psychoanalysis of the bind Configurations, which is based on Freudian Psychoanalysis, but it extends its field of approach to the group. The link is the main concept that singles out this theory, since it points to the existence of a group psychic apparatus and requires the triangulation, I - others - connector, in which the connector is what exists in common and supports the link. The discussion will be illustrated excerpts from an interview with Tiago, a child who had a tumor of the central nervous system (CNS), who was not in oncological treatment and had lower vision due to the disease and oncologic therapy. His position in the family group is discussed as a "symptom carrier" of an anguishing situation. There is a misunderstood alliance around the permanent after- effectand he takes a passive stance to protect the parents from distress. The insertion of the psychoanalyst in specialized centers for the treatment of childhood cancer opens the possibility of interventions in situations in which parents deny the anguish and difficulties. There is the bet that, by providing a space for listening and observing questions related to family dynamics, one can clarify the places of each member and work in favor of the elaboration of what is being lived, contributing to the formation of less alienating bonds .

Key Words: Psychoanalysis of the Linking Configurations, Unconscious Alliance, Tumor of the central nervous system.
\end{abstract}

* Doutora pela Universidade de São Paulo, Brasil (2017). Professora Adjunta - A da Universidade Federal do Sul da Bahia

* Psicóloga pela Universidade Tiradentes, Mestre em Psicologia Clínica pela USPSP, Psicóloga do Centro de Oncologia do Hospital Primavera. 


\section{Introdução}

A Psicanálise Vincular ou das Configurações Vinculares teve sua origem na França, tendo como principal teórico René Kaës e, sua base é a Psicanálise Freudiana (Gomes \& Levy, 2009). Freud inaugura um novo campo de prática e pesquisa sobre a psique ao formular o conceito de inconsciente e, por extensão, o sujeito do inconsciente. $\mathrm{O}$ inconsciente, formulado por Freud, não é lugar de irracionalidade e nem está oculto da consciência, ele designa um sistema psíquico que apresenta uma lógica própria de funcionamento que estrutura e marca o sujeito (Cukiert \& Priszkulnik, 2001). O inconsciente é o maior representante da realidade psíquica, que é o mundo interno do sujeito, formado pelo desejo inconsciente e pelas fantasias que lhe estão ligadas (Laplanche e Pontalis, 2001).

Esse desejo é resultado da articulação entre os elementos significantes, que se constituem a partir do outro simbólico, primordialmente a mãe e o pai (Cirino, 2001). Esses constroem, antes do nascimento biológico da criança, uma trama, dotada de desejo inconsciente e de lugares imaginários, onde inserem o filho, que através da fala que as pessoas lhe direcionam, apreende esses elementos do pai, da mãe e, posteriormente, da cultura (Priszkulnik, 2009). O sujeito se constitui a partir dos sentidos que dá aos elementos que lhe são fornecidos, com essa acepção, a criança também participa de sua constituição subjetiva. Assim, a criança que interessa a psicanálise é marcada pelo inconsciente, sendo capaz de elaborar um saber sobre a sua realidade psíquica, constituída de desejos inconscientes e de fantasias a eles vinculadas (Cirino, 2001).

A Psicanálise dos processos individuais - Freudiana - e a Psicanálise dos processos intersubjetivos - Vincular - apresentam numerosos pontos de convergência. Porém esta última estende o campo da primeira para abordagem do grupo (Kaës, 2011). Ele amplia a noção de sujeito do inconsciente e concebe o sujeito da herança, que se constitui no espaço intersubjetivo pela transmissão psíquica (Gomes \& Levy, 2009). A transmissão psíquica geracional ocorre em um contexto de vínculo.

Segundo Moguillansky (2008), a noção de vínculo surge da necessidade teórica de pensar a dimensão intersubjetiva da constituição do sujeito e do aparelho psíquico grupal. Por esse motivo, Kaës (2011) aponta que existe o inconsciente intrapsíquico, conforme Freud elabora, e algumas das formações inconscientes são deslocadas, expostas e depostas em lugares psíquicos que o grupo que o sujeito pertence - predispõe e que o sujeito utiliza e partilha. Essas formações são significadas por cada membro do grupo, que responde a essas significações de acordo com o lugar que ocupa no grupo. Esse processo compõe o aparelho psíquico grupal.

Vínculo é uma estrutura inconsciente grupal criada pelos sujeitos, dando-lhes pertencimento (Gomes \& Levy, 2009). O vínculo exige a triangulação eu - outro(s) - conector, em que o conector é o que o que existe de comum e sustenta o vínculo, podendo ser um segredo, uma aliança, um sonho, um sintoma (Berenstein, 2008). Logo, para a criação e manutenção do vínculo é necessária interação entre os sujeitos do grupo, configurando um processo dialético de comunicação e aprendizagem, em que o inconsciente de cada membro se inscreve e se manifesta configurando uma zona comum e partilhada (Gomes \& Zanetti, 2009).

Um vínculo não pode se basear nem na exclusividade da diferença nem na exclusividade da semelhança, é necessário haver uma continuidade e descontinuidade entre o eu e o outro, um espaço comum e partilhado e um espaço singular e diferente, só assim o sujeito pode partilhar e ser partilhado. Moguillansky (2008) enfatiza que, mesmo em seu melhor rendimento, no vínculo, é preciso ter uma alternância entre estados fusionais, ou seja, sem alteridade, sendo o enamoramento seu melhor modelo, e estados em que a desilusão pode ser contida e se conceber a alteridade.

Conforme dito, as alianças inconscientes são o fundamento para o processo de formação de vínculo, em que, através de um pacto ou um contrato com o grupo, o sujeito renuncia uma parte de si em troca de uma parcela de segurança para o grupo e para si mesmo, enquanto pertencente a ele (Castanho,2011). Neste sentido, as alianças inconscientes são um dos pontos de passagem e das linhas de ruptura entre o espaço intrapsíquico e o espaço intersubjetivo, desempenhando o papel determinante na constituição do inconsciente grupal, do sujeito, na manutenção dos vínculos e na formação de sintomas (Kaës, 2011).

Sabe-se que uma doença orgânica crônica e a elaboração das perdas decorrentes dela são situações de crise familiar, pois exigem significações e remanejamento dos lugares ocupados pelos sujeitos no vínculo. Muitas vezes, ocorre revelação de algumas alianças inconscientes e formação de novas, que pode não implicar em menor sofrimento. $\mathrm{O}$ câncer vai além da história médica e se insere na história familiar, ter uma criança com o histórico de câncer e com sequelas orgânicas decorrentes do tratamento da doença devem proporcionar no grupo 
familiar conflitos referentes, sobretudo, ao futuro dela. É uma criança saudável? Será que poderá apresentar uma vida produtiva? Precisará sempre de alguém para acompanhá-la?

Diante desse contexto, a família vivencia uma sensação de desamparo e angústia. É em torno deste tema que este texto abordará as noções de vínculo e de aliança inconsciente.

\section{Metodologia}

Este trabalho é originado da pesquisa de mestrado intitulada "A criança com tumor de sistema nervoso central: considerações da psicanálise para a área da saúde" (Almeida, 2011), que utilizou o método clínico qualitativo, formulado por Turato (2003). Para aplicação do método, foram feitas entrevistas semi dirigidas de questões abertas com onze crianças que tiveram tumor de sistema nervoso central e estavam fora de tratamento oncológico. Essa pesquisa foi aprovada pelo Comitê de Ética em Pesquisa da Casa de Saúde Santa Marcelina.

As entrevistas semi dirigidas caracterizam-se pela alternância de direção: o entrevistado fica aberto para responder as perguntas, associando livremente suas ideias sobre o assunto, porém o entrevistador direciona o tema da resposta a partir das questões disparadoras. É necessário que o entrevistador tenha uma postura clínica de acolhimento das emoções e dos sentimentos mobilizados pela situação.

Para ilustrar a discussão deste trabalho, selecionou-se trechos de uma entrevista, realizada com Tiago (nome fictício) de 8 anos e 6 meses. Tiago teve o diagnóstico de Astrocitoma Pilocítico, de localização fronto-parietal, aos 5 anos e 5 meses. O tratamento realizado foi punção de alívio e ressecção do tumor. O pai do entrevistado concordou com a participação voluntária da criança e assinou o Termo de Consentimento Pós-Informação. O paciente assentiu em participar

Astrocitoma Pilocítico é um tipo de tumor de Sistema Nervoso Central (SNC), frequentemente cístico, considerado grau I pelo Instituto Nacional do Câncer (INCA). O INCA (2008) adota os critérios da Classificação Internacional do Câncer Infantil (CICI), proposta pela Agência Internacional para Pesquisa em Câncer (IARC - International Agency for Research on Câncer), para descrever as características do câncer da criança e do adolescente.

Em termos mundiais, os dados da Organização Mundial de Saúde / OMS apontam que mais de 150.000 crianças são diagnosticadas com câncer por ano no mundo (Verdélio, 2016). Por região brasileira, os maiores índices estão nas Regiões Sudeste, com 6.050 casos e Nordeste, com 2.750 novos pacientes. Em seguida, estão as regiões Sul - 1.320 novos casos, Centro-Oeste, com 1.270 casos e Norte, estimando 1.210 casos novos (INCA, 2015). O percentual para tumores cerebrais varia de $8 \%$ a $15 \%$ de todas as neoplasias malignas pediátricas, sendo o mais frequente tumor sólido na faixa etária pediátrica. Os tumores de SNC ocorrem, principalmente, em crianças menores de 15 anos, com um pico de incidência na idade de 10 anos (INCA,2015).

Para a maioria dos países, inclusive o Brasil, o tipo de câncer infanto-juvenil mais comum é a leucemia, sendo o percentual médio entre $25 \%$ a $35 \%$ de todos os cânceres pediátricos. Nos países desenvolvidos, os linfomas correspondem ao terceiro tipo de câncer mais comum, porém, na maioria das regiões do Brasil, esse tipo equivale ao segundo lugar, sendo seguido pelos tumores de SNC (INCA,2015).

Com relação ao tumor de SNC seu pico de incidência é na primeira década de vida. O quadro sintomatológico é rico e depende da localização da doença, sendo os principais sinais: cefaleia, náuseas, vômitos, ataxia, alterações visuais e da fala, distúrbios de deglutição e endocrinológicos, convulsão, confusão mental e alterações de comportamento, como irritabilidade e letargia (Silva, Barreto \& Pianovski, 2007). O tratamento varia de acordo com a localização e histologia da neoplasia, sendo a ressecção cirúrgica do tumor o tratamento de melhor prognóstico, seguido da quimioterapia e radioterapia, na maioria das vezes, usadas como adjuvantes para o primeiro tipo de tratamento citado (Nathan, Patel, Dilley, Goldsby, Harvey, Jacobsen, Kadan-Lottick, McKinley, Millham, Moore, Okcu, Woodman, Brouwers \& Armstrong, 2007).

Essa diversidade de tratamento trouxe para os pacientes uma chance maior de sobrevida e, só a partir do aumento no número de sobreviventes que os oncologistas pediátricos puderam observar os efeitos do tratamento oncológico. Osório, Camargo, Lopes, Bastos, Wajman e Thompson (2003, p. 381) destacam que as sequelas cerebrais "podem ser subdivididas em estruturais, neuroendócrinas (em 80\% pós-radioterapia) e neurocognitivas". As manifestações das sequelas neuropsicológicas são evidenciadas, em média, entre um e três anos após o tratamento oncológico. Outras sequelas decorrentes do tratamento clínico são: redução no crescimento da estatura do paciente, prejuízos ou perda de visão, efeito ototóxicos agudos e tardios, retardo na menarca, dis- 
função gonodal, epilepsia e segunda neoplasia (Rigon Júnior, 2002).

A entrevista com Tiago não teve o objetivo de avaliar os efeitos neuropsicológicos. Porém, como um dos critérios para a seleção dos pacientes para a entrevista era ter sequelas aparentes decorrentes do tumor e do tratamento oncológico, a pesquisadora leu no prontuário que o menino apresentava perda de visão e que a equipe médica conversou com os pais que essa perda é definitiva, sem possibilidade de correção por meio de óculos, pois é um dano no cérebro, porém eles tinham dificuldade em aceitar.

\section{Resultados e Discussão}

Antes da realização da entrevista, a pesquisadora conversou com o pai e a criança, que estava usando óculos. Após obter a autorização da participação voluntária da criança na pesquisa, o pai saiu da sala para que ocorresse a entrevista. A sós com a criança, a entrevistadora sentou ao seu lado e, durante a entrevista, a pesquisadora percebeu que a criança tirou os óculos.

No início da entrevista, Tiago resiste em falar diretamente sobre o rebaixamento da visão. Primeiramente, ele fala que tem dificuldade em ler na lousa e depois ele fala do uso dos óculos, deixando entender que seus pais não conseguem aceitar que sua visão foi diminuída após o tumor cerebral e procuram meios para ajudá-lo enxergar melhor:

Quando eu fui fazer aquele teste lá, aquele teste na minha Igreja, o pastor levou uns óculos pra me ver. Ai escolheram, escotheram minha mãe e meu pai escolheram, escolheram, escolheram depois eles compraram. Aí chegon o dia de ir lá pegar o óculos, era um igualzinho esse aqui só que esse negócio vinha daqui até aqui, ai en abri e coloquei. [...] Ai teve outro, en tava brincando de pega-pega. Ai minha lente caiu, quer dizer ele achou minha lente. Eu nem percebi é que minha lente tinha soltado.

A repetição da palavra "escolheram" aponta que Tiago estava fora da decisão sobre o uso dos óculos, tendo como função "abri e colocar". O fato dele "nem perceber que a lente soltou" indica uma falta de interesse com o objeto, apontando para uma posição passiva em seu uso.

Kaës (2011) afirma que o sujeito não é dividido somente a partir dos conflitos internos, ele também se divide entre a realização de seu próprio fim e o lugar que ele deve assumir nos vínculos que o constituíram. Infere-se que a posição de Tiago neste grupo familiar é de "porta-sintoma" ou "porta-palavra" de uma situação angustiante, havendo uma aliança de mal entendido em torno da sequela permanente. Apesar da falta de visão ser algo dito pelos médicos, em consulta, a entrevista com Tiago indica que a angústia decorrente dessa constatação é um sentimento comum entre os pais, porém não dito. Raciocina que esta angústia advém da sequela que marca a limitação da criança, as dúvidas quanto ao futuro e também lembra o histórico da doença grave. Esse indizível é encoberto por atitudes compensatórias que buscam negar a sequela.

Essa angustia decorrente da perda da visão de Tiago encontra ressonância na literatura freudiana, Freud (1919/1996) constata que o medo de ferir ou perder os olhos é o dano físico mais temido pelos adultos que ele teve contato em sua experiência clínica. Ele associa que "o medo de ficar cego é, muitas vezes, um substituto do temor de ser castrado" (p.249).

A angústia de qual trata a psicanálise, é a angústia existencial, ligada a sensação de desamparo provocada quando o sujeito é confrontado com um outro, considerado onipotente, que o invade, evoca o medo e ele não consegue ter qualquer reação (Freud 1919/1996). Dejours (1988), resumindo a obra de Freud sobre esse tema, afirma que ele percorre um caminho muito rico de elaborações sobre a angústia, conferindo-lhe dois tipos diferentes: angústia somática - tensão física e angústia psíquica - afeto. Conforme Dejours esclarece, Freud retira as alterações físicas do sinal de angustia do campo de investigação da psicanálise e os aspectos somáticos da angústia se encontram na atuação da medicina.

Em psicanálise, a angústia se caracteriza pela impossibilidade para o sujeito de utilizar a palavra como mediadora, ocorrendo o silêncio e, posteriormente, exprimindo o contrário daquilo de que indica a aflição (Mannoni, 1985). Esse mecanismo para mascarar a angústia ocorrem porque o inconsciente não aguenta a sensação desse afeto por muito tempo e, por isso, a pessoa procura, através de comportamentos, palavras ou pensamentos, fugir.

Brun (1996, p. 225) contribui com isso ao dizer, quando "no calor das coisas a representação da perda adquire um excesso de realidade no que respeita a vida psíquica, os pais reagem sem medir plenamente a natureza de seus atos". A presença de obstáculos decorrentes da deficiência expõe pais e filhos à tomada de consciência da impotência de cada um. A impotência dos pais em responder às perguntas do filho, em lhe dizer quando vai melhorar. A impotência do filho para retomar suas atividades anteriores e para recobrar sua integridade física. Então, os pais, acreditando agir para o bem do filho, tentam ocultar aquilo que confirma as impossibilidades.

Brun (1996) escreve que eles realizam manobras ilusórias que exercem influência sobre o futuro. "As me- 
didas dirigidas a adaptar o meio ambiente, ao invés de permitir à criança adaptar-se a ele, não têm pois o efeito pacificador previsto", pois a criança vê nessas medidas a prova de que "seu sentimento de perda é partilhado por seus próximos e que eles sofrem com isso" (p. 226). Secundária a essa percepção, a criança pode sentir angústia de magoar seus pais e, para contentar os que o cercam, a criança suprime sua originalidade e autonomia. Durante a entrevista, Tiago demonstra que sabe do efeito permanente do tumor em sua visão, porém suprime essa constatação adotando uma posição passiva de proteger os pais da angústia.

Kaës (2011) conceitua sobre os espaços psíquicos do grupo: o singular privado, o comum, o partilhado e o diferente. O primeiro corresponde ao espaço psíquico individuado que marca a estrutura, a história e a subjetividade de um sujeito, sendo que a singularidade do espaço psíquico privado coexiste com as zonas de realidade comuns e partilhadas.

Já a substância psíquica comum corresponde a união da fantasia, sonho, desejo, identificações, ideais, significantes, ilusão, alianças inconscientes, que são membros de um vínculo, não existindo vínculo sem essa substância psíquica comum (Kaës,2011).

O espaço psíquico partilhado corresponde a parte que toma cada sujeito ou o lugar próprio que ele ocupa, sendo que um é ator passivo ou ativo ou observador da ação psíquica. O lugar ocupado é o lugar que é próprio do sujeito que o singulariza no grupo. Sustentar o vínculo exige o abandono ou a perda de certos limites individuais, uma certa indiferenciação, mas que serve de base para que o sujeito apareça em sua singularidade (Kaës,2011).

Tiago usa os óculos quando o pai está na sala, porém quando o pai sai, ele se permite tirar os óculos, marcando sua diferença em relação ao grupo.

É neste sentido que Tiago revela para a entrevistadora seu saber:

Por exemplo o que, é, vejamos, [meu pai] me ajuda, me ajuda em coisa. Um dia ele me ajudou fazer a lição de casa da outra professora, que nem sair daqui e vai reto, reto, reto, é o P. É que no P. não é que nem o A., o P. é a escola, pessoal pra mim assim que uso óculos.[...] Se acostumando, é saber que não tem mais visão, eu já quebrei uns 7, 6 óculos, ai, olha esse aqui, coloca o dedo ô, ta vendo, essa lente aqui já ta quase saindo já, essa aqui também. Só que essa daqui, já tá saindo.
A associação feita por Tiago - "saber que não tem mais a visão" e "já ter quebrado entre 7 e 6 óculos" suscita que ele utiliza de uma parapraxia para escapar do conflito entre o personagem que os pais o delegam encarnar e aquele que ele pressupõe ser, pois como ele diz, os óculos não o ajudam enxergar melhor.

Entrevistadora (E): Porque você precisou usar óculos? Criança (C): Porque eu precisei.

E: E o óculos faz você enxergar tudo ou mesmo com o óculos você tem dificuldade?

C: É que sem óculos eu consigo ver melhor, sem o óculos eu consigo ver, é tudo mais claro, tudo mais bonito, tudo isso.

E: Sem o óculos você ver?

C: Tudo bem. Sem o óculos, ô, a cadeira não tá azul escuro. Então, com coloco o óculos (põe o óculos) eu vejo que é roxo, um pouquinho roxinho. (Tira o óculos) $\hat{O}$, agora ficou bom.

E: Sem o óculos você enxerga melhor?

C: Sim.

As parapraxias são conceituadas por Freud no texto "O interesse científico da Psicanálise" (1913/1996). O autor salienta que as parapraxias ocorrem em pessoas sadias e normais e exemplifica que são esquecimentos de palavras e nomes que são familiares, esquecimento do que pretendia fazer, lapsos de linguagem e de escrita, erros de leitura, colocação de coisas em lugares errados e incapacidade de encontrá-las, perda de objetos, acidentes sérios:

Todos esses fatos ... foram classificados como exemplos de "distração", sendo atribuídos à fadiga, à falta de atenção ou aos efeitos colaterais de certas doenças leves. A indagação analítica, contudo, demonstra com certeza suficiente para satisfazer a todos os requisitos, que estes últimos fatores operam simplesmente como facilitadores e podem achar-se ausentes. As parapraxias são fenômenos psíquicos plenamente desenvolvidos e sempre possuem um significado e uma intenção. Servem a propósitos definidos que, devido à situação psicológica predominante, não podem ser expressos de nenhuma outra maneira. Essas situações, via de regra, envolvem um conflito psíquico que impede a intenção subjacente de encontrar expressão direta e a desvia ao longo de caminhos indiretos (Freud, 1913/1996, p.170).

Exemplificando os sintomas, Kaës (2011) informa que eles "são produzidos e mantidos pelos membros do 
grupo devido à função que eles cumprem na vida psíquica de cada um deles e, simultaneamente, no processo grupal". Este raciocínio pode ser transposto para a aliança inconsciente, e no caso relatado neste texto, ela tem o propósito de conter a angustia decorrente da constatação da limitação em Tiago. É uma ilusão achar que as atitudes de encobrir a limitação diminuem o sofrimento, pois elas não criam possibilidades de metabolização e integração das perdas decorrentes do tumor e do tratamento oncológico (Gomes \& Zanetti, 2009).

Dolto (1984/2007, pp.12 e 13) esclarece:

quando uma criança é atingida por uma enfermidade, é indispensável que seu déficit físico lhe seja explicitado.... Essas trocas humanizantes - ou pelo contrário, sua ausência desumanizante - provêm do fato de terem ou não os pais aceito a enfermidade do corpo de seu filho

O não-dito pode representar um fato que reclama um sentido, e a falta deste sentido impede as transformações criativas que favorece o trabalho de elaboração das sequelas e das limitações decorrentes.

\section{Considerações Finais}

Este caso exemplifica que os déficits sofridos pela criança que teve câncer podem ser encarados pelos pais como uma deficiência que os atinge no plano narcísico e, como refere Mannoni (1985), "dá-se uma perda brusca de toda referência de identificação" (p.2). Nesse caso, os pais demoram de se reconhecer em seus papéis, pois o equilíbrio deles é atingido por aquilo que falta no filho. Segundo a autora, os pais se vêem diante da angústia e, para se protegerem dessa sensação incômoda, apresentam comportamentos impulsivos que visam mascará-la.

A inserção do psicanalista nos centros especializados de tratamento do câncer infantil abre a possibilidade de intervenções em situações em que os pais negam as angústias e as dificuldades. Há a aposta que, proporcionando um espaço para serem escutadas e observadas questões referentes à dinâmica familiar, podem-se esclarecer os lugares de cada membro no grupo familiar e trabalhar no sentido de favorecer a elaboração do que está sendo vivido, contribuindo para a formação de vínculos menos alienante.

Trabalhar com os pais a necessidade de reconhecer o filho como pessoa, é ajudá-los no desamparo que a doença da criança os coloca. Não se pode exigir que situações de adoecimento de um filho não tenham incidência nos pais. Perante as situações de desamparo, o semelhante serve de bengala para o sujeito. Nesse sentido, uma das formas de presença do analista é ser a bengala que segura e organiza o sujeito. No caso das crianças com câncer, o trabalho psicanalítico beneficia os pais se re-situarem na relação com os filhos, aliviando sintomas que podem ser de ordem inconsciente, mas intensificam os sinais orgânicos da doença da criança.

\section{Referências}

Almeida, M. (2011). A criança com tumor de sistema nervoso central: considerações da psicanálise para a área da saúde. Dissertação de Mestrado, Instituto de Psicologia, Universidade de São Paulo, São Paulo. Recuperado em 11 de Junho, 2013 do http://www.teses.usp.br/teses/disponiveis/47/47133/ tde-04062012-110150/pt-br.php

Berenstein, I. (2008). Del ser al hacer: curso sobre vincularidad. Buenos Aires: Paidós Brun, D. (1996) A criança dada por morta: riscos psíquicos da cura. (J. Neto, J. Souza e M. Werneck, trads.). São Paulo: Casa do Psicólogo.

Castanho, P. (2011). Uma cultura da violência em uma região periférica de São Paulo. In M. Bialer (org.) O trabalho PSI na saúde pública. Ribeirão Preto / SP: Novo Conceito.

Cirino, O. (2001). Psicanálise e Psiquiatria com crianças: desenvolvimento ou estrutura. Belo Horizonte: Autêntica.

Cukiert, M. \& Priszkulnik, L. (2001). O ego e o corpo na teoria freudiana: algumas considerações. Anais do I Congresso de Psicologia Clínica, São Paulo: Universidade Presbiteriana Mackenzie, v, 1, 378-382.

Dejours, C. (1988). O corpo entre a biologia e a psicanálise. (D. Vasconcellos trad.) Porto Alegre: Artes Médicas.

Dolto, F. (2007) A imagem inconsciente do corpo (N. Moritz \& M. Levy, trads., 2 a ed.) São Paulo: Perspectiva (Trabalho original publicado em 1984)

Freud, S. (1996). O estranho. In: Edição Standard Brasileira das Obras Psicológicas Completas de Sigmund Freud. (J. Salomão trad., vol. XIV, pp. 235-269). Rio de Janeiro: Imago (Trabalho original publicado em 1919)

Freud, S. (1996). O interesse científico da Psicanálise. In: S Freud, Edição Standard Brasileira das Obras Psicológicas Completas de Sigmund Freud. (J. Salomão trad., vol. XIII, pp. 167-192). Rio de Janeiro: Imago (Trabalho original publicado em 1913).

Gomes, I. \& Levy, L. (2009, Janeiro - Junho). Psicanálise de família e casal: principais referenciais teóricos e perspectivas brasileiras. Aletheia (ULBRA), $29,151-160$

Gomes, I. \& Zanetti, S. (2009, Janeiro - Março). Transmissão Psíquica Transgeracional e construção de subjetividade: relato de uma psicoterapia psicanalítica vincular. Psicologia USP, 20 (1), 93 - 108.

Instituto Nacional de Câncer (2008). Câncer da criança e do adolescente no Brasil: dados dos registros de base populacional e de mortalidade. Recuperado em $17 \mathrm{de}$ Maio de 2010 de http://www1.inca.gov.br/tumores_infantis/pdf/livro_tumores_infantis_0904.pdf

Instituto Nacional de Câncer (2015) Estimativa 2016: incidência de câncer no Brasil. Rio de Janeiro: INCA, 126p. Recuperado em 15 de março de 2016, de http://www.inca.gov.br/bvscontrolecancer/publicacoes/edicao/Estimativa_2016.pdf

Kaës, R. (2011) Um singular plural: a psicanálise à prova do grupo (L. P. Rouanet, trad.). São Paulo: Edições Loyola.

Laplanche, J. \& Pontalis, J. (2001). Vocabulário da Psicanálise. São Paulo: Martins Fontes.

Mannoni, M. (1985). A criança retardada e a mãe (M. R. Duarte, trad., M. S. Silva, rev.). São Paulo: Martins Fontes.

Moguillansky, R. (2008) Representação, relação de objeto e vínculo: uma visão pessoal sobre a "noção de vínculo". In I. C. Gomes (coord.) Família: diagnóstico e abordagens terapêuticas. Rio de Janeiro: Guanabara Koogan.

Nathan, P., Patel, S., Dilley, K., Goldsby, R., Harvey, J., Jacobsen, C., Kadan-Lottick, N., McKinley, K., Millham, AK., Moore,I., Okcu,MF., Woodman,CL., Brouwers,P., Armstrong, FD. (2007, August) Guidelines for identification of, advocacy for, and intervention in neurocognitive problems in survivors of childhood cancer: a report from the children's oncology group. Arch Pediatric Adolesc Med, 161 (8), $798-806$. 


\section{VÍNCULO E ALIANÇA INCONSCIENTE: REFLEXÕES A PARTIR DE ENTREVISTA COM CRIANÇA COM SEQUELA ONCOLÓGICA}

Osório, C., Camargo, C., Lopes, L., Bastos, F., Wajman, J. \& Thompson, T. (2003). Seqüelas neurocognitivas da radioterapia cerebral em crianças com tumores intracranianos. In C. A. M. Osório. Neurologia oncológica - manejo multidisciplinar das neoplasias do sistema nervoso central da infância (pp. 381-393). São Paulo: Lemar.

Priszkulnik, L. (2009). A criança que a psicanálise freudiana descortina: considerações. In D. Rose Júnior et al (org.) Esporte e atividade física na infância e na adolescência: uma abordagem multidisciplinar. (2 ${ }^{\mathrm{a}}$ ed., pp. 11-22). Porto Alegre: Artmed.

Rigon Júnior, H. (2002). Avaliação dos efeitos tardios em sobreviventes de câncer na infância. Dissertação de Mestrado, Fundação Antônio Prudente, São Paulo.

Silva, D., Barreto, J. \& Pianovski, M. (2007) Diagnóstico diferencial dos tumores sólidos. In: F. A. Lopez \& D. Campos Júnior, (Org.) Tratado de pediatria (pp. 1651-1660) Barueri, SP: Manole.
Turato, E. (2003) Tratado da Metodologia da Pesquisa Clínico-Qualitativa: construção teórico-epistemológica, discussão comparada e aplicação nas áreas da saúde e bumanas (2a ed.). Petrópolis/RJ: Vozes

Verdélio, A. (2016, 15 de fevereiro). Câncer infantil: taxa de cura no Brasil é a mesma há 30 anos. Agência Brasil. Recuperado em 15 de setembro de 2016, de http://agenciabrasil.ebc.com.br/geral/noticia/2016-02/cancer-infantil-taxa-de-cura-no-brasil-e-mesma-ha-30-anos

Submetido em: 29-7-2017

Aceito em: 20-12-2018 